\title{
Territorial indicators for policy purposes: NUTS regions and beyond
}

Teodora Brandmueller

Eurostat

E-mail:

teodora.brandmueller@ec.europa.eu

Gunter Schäfer

Eurostat

E-mail:

gunter.schaefer@ec.europa.eu

Petri Ekkehard

Eurostat

E-mail: ekkehard.petri@ec.europa.eu

Oliver Müller

Eurostat

E-mail: oliver.muller@ec.europa.eu

Valeriya Angelova-Tosheva

Eurostat

E-mail:

valeriya.angelovatosheva@ec.europa.eu
Regional statistics, along with the NUTS Nomenclature des Unités Territoriales Statistiques, or Nomenclature of Territorial Units for Statistics) classification, already have a solid tradition. They have developed into a very useful tool for detailed analyses and have become the basis for important decisions in the allocation of EU funding. Gradually, the scope of regional statistics has widened, and regional statistics now play a role in several statistical domains with a wide range of statistical indicators.

The recognition that many of the social and economic issues Europe faces today have urban or rural characteristics has led to an initiative to supplement statistical data on NUTS regions with data on cities and rural areas. These sub-national statistics allow policy makers to better target their policies. For example, in some parts of Europe, poverty and social exclusion are clearly an urban problem, while in other areas they are primarily a rural problem.

A further aspect that has gained considerable importance in territorial policy making - as well as in public awareness - concerns the so-called functional regions, which are selected or constructed from more detailed geographical units according to specific features. The labour market area is one example of this type of functional delineation, which helps to shed light on important territorial characteristics.

The fast-growing use of geographic information and new technical facilities has 
Keywords: related perspectives. They can be com-

NUTS, bined in multiple ways to create new pos-

Cohesion Policy, sibilities for policy analysis and to illus-

urban-rural classification, trate social and economic characteristics at

opulation grid varying levels of geographic detail.

\section{Meeting the information needs of territorial policies with Euro- pean statistics}

European statistics are the relevant statistics needed to assess the performance of EU activities. The EU places considerable emphasis on regional policy, aiming to bring Europe's regions and cities closer together in economic, social, and environmental terms. European sub-national statistics are important for understanding and quantifying the impact of policies on a specific region or area. Regional and other sub-national statistics available within Europe are thus a helpful tool for understanding territorial diversity. Most of the statistical information need to be met at the EU level comes from the Cohesion Policy.

\section{Cohesion Policy}

The Lisbon Treaty specifically introduced the objective of territorial cohesion among the twin goals of economic and social cohesion (Articles 174 to 178 of the Treaty on the Functioning of the European Union; see References). Developing policies for increasing overall cohesion requires recognising the particular characteristics of certain regions, cities, or areas. The EU's Cohesion Policy aims to invest in growth and jobs, and to promote territorial cooperation. Cohesion Policy funding for the 2014-2020 period is foreseen to be almost EUR 352 billionequivalent to almost one-third of the EU's total budget during that period. Regional

Regional Statistics, Vol. 7. No.1. 2017: 078-089; DOI: 10.15196/RS07105 
statistics are employed to allocate funds and determine geographic eligibility on the basis of regional GDP per inhabitant in purchasing power standards (PPS), averaged over a three-year period. NUTS level 2 regions were ranked and split into three groups:

- less developed regions (where GDP per inhabitant in PPS was less than 75\% of the EU average);

- transition regions (where GDP per inhabitant in PPS was between $75 \%$ and $90 \%$ of the EU average); and

- more developed regions (where GDP per inhabitant in PPS was more than $90 \%$ of the EU average).

More than half of the foreseen Cohesion Policy funding is allocated to less developed regions.

The nature of the Cohesion Policy and its objectives have evolved in recent decades. In addition to its focus on reducing economic disparities, the policy has become more closely aligned with the overall strategy of the EU. Accordingly, in the 1990s, funding was extended to environmental and trans-European transport infrastructure. In the 2000s, the Cohesion Policy was directed toward the pursuit of the Lisbon and Gothenburg strategies for growth and sustainable development. Currently, the Cohesion Policy is an integral part of the Europe 2020 strategy, with a strong focus on employment, innovation, sustainability, and reducing poverty and social exclusion. This shift is accompanied by an increased demand for regional statistics on sustainable growth as well as a recognition of the need to move beyond GDP when assessing territorial development.

\section{Regional statistics by NUTS regions: A classic approach that has a future}

Regional statistics are based on a harmonised convention in the definition of regions contained in the classification of territorial units for statistics, known by the acronym NUTS (Nomenclature des Unités Territoriales Statistiques, or Nomenclature of Territorial Units for Statistics; see References). This is a regional classification for EU member states that provides a harmonised hierarchy of regions. The NUTS classification subdivides each member state into regions at three different levels, covering NUTS 1, 2, and 3 from larger to smaller areas. If available, administrative structures are used for the different NUTS levels. In Germany, for example, there are 16 NUTS level 1 regions, corresponding to the states (Bundesländer); 38 NUTS level 2 regions, corresponding to government regions (Regierungsbezirke); and more than 400 NUTS level 3 regions, corresponding to districts (Kreise). In those member states where there is no administrative layer corresponding to a particular level, artificial regions are created by aggregating smaller administrative regions. The NUTS classification is defined in Regulation

Regional Statistics, Vol. 7. No.1. 2017: 078-089; DOI: 10.15196/RS07105 
(EC) No 1059/2003 of the European Parliament and the Council. It defines the minimum and maximum population thresholds for the size of NUTS regions. Regions have also been defined and agreed upon by the European Free Trade Agreement (EFTA) and candidate countries on a bilateral basis.

For statistical purposes, the NUTS classification has significant advantages. First, NUTS gives clear preference to established administrative units with identifiable governing structures or aggregations of such units. Second, the administrative nature implies the existence of structures that strongly support the collection of statistics, such as registries or clearly defined competences for the administrative unit. Finally, the NUTS classification achieves a common spatial reference for very different statistical indicators.

Based on NUTS, there is a more than 30-year tradition of EU regional statistics, which has gradually extended to almost all domains of the main social and economic themes. Today, regional statistics cover a broad range of statistical areas: economic accounts, demography, labour market, education, health, agriculture, business, tourism, science and technology, transport, digital economy and society, poverty, crime, social exclusion, etc. It is a field of growing coverage and importance.

An important advantage of regional statistics is the ability to combine different indicators to create new insights. Eurostat offers several interactive applications on its website for visualising regional data. A good example is the Regions and Cities Illustrated tool, which includes a wide range of indicators. There are four standard visualisations: a distribution plot, a scatter plot, a bar chart, and a data table. These provide opportunities to perform deeper analyses of regional data as well as comparisons and rankings of different regions. The scatterplot can be used to explore relationships between different indicators and find regions with similar characteristics. In addition, an animated timeline can be used to explore how indicators for specific regions have developed over time. Figure 1 shows a screenshot of the tool.

Regional Statistics, Vol. 7. No.1. 2017: 078-089; DOI: 10.15196/RS07105 
Figure 1

Employment and unemployment rates in selected NUTS 2 regions, 2015

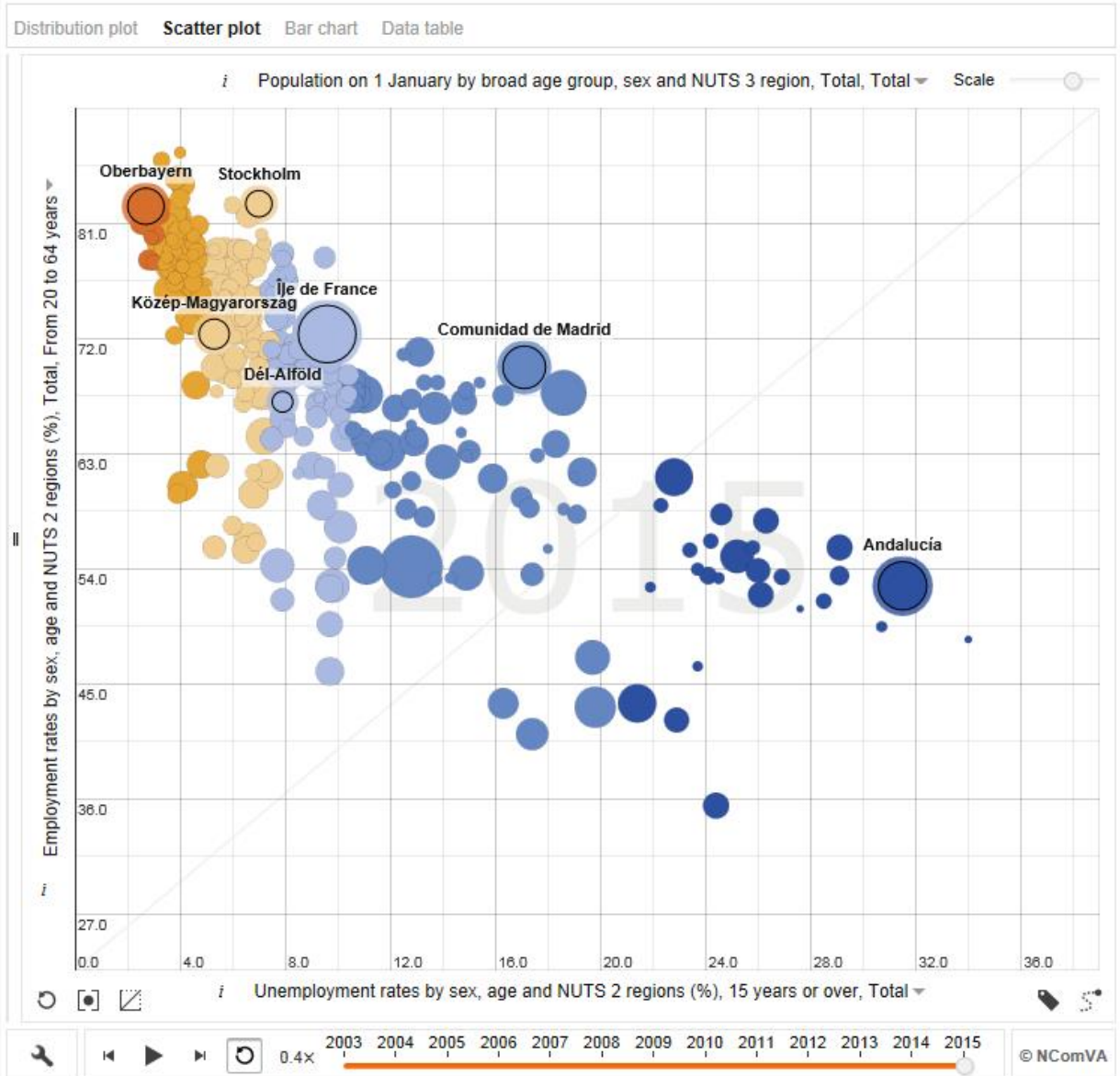

Source: Eurostat/Regions and Cities Illustrated.

Reading note: On the chart, each bubble represents a NUTS level 2 region. The size of the bubble reflects the total population of the region. The employment rate among persons aged 20-64 is shown on the vertical axis while the unemployment rate of persons aged 15-74 is shown on the horizontal axis.

The key factor that influences the evolution of regional statistics is the trade-off between the need for more detailed information and the costs (including the burden on respondents) of data collection. For survey-based statistics, it is evident that the lower the regional breakdown, the larger the sample size required for reliable figures. The current trends in statistics toward increasingly relying on open data, big data, and administrative sources, as well as promoting the reuse of existing data across different statistical domains, will in the long run promote the further evolution of regional statistics. 
In some key areas, further developments of regional statistics are taking place to strengthen the utility of regional indicators for policy making:

- Regional accounts: Regional accounts data collection now follows the new European System of Accounts 2010 (ESA 2010) methodology. In 2017, Eurostat is expected to release complete tables to users following the new methodology, including back data as from reference year 2000 .

- Regional poverty and social exclusion: The Europe 2020 strategy has resulted in increased public discussion about the factors that determine poverty and social exclusion. Currently, the at-risk-of-poverty and social-exclusion rates, and their three sub-components, are not available as data for all EU countries at NUT level 2. For policy development, monitoring, and evaluation in this domain, policy makers have requested regional data for the future. If all the works initiated in this domain deliver the expected results, a majority of countries will be able to deliver NUTS level 2 data with the required precision by 2019 .

- Regional population projections: Eurostat released population projections using data for 1 January 2013. The projections result from the application of a set of assumptions about future developments in fertility, mortality, and net migration. They cover population developments from 2013 to 2080.

\section{Urban-rural classifications}

In the past, the NUTS classification has facilitated the collection, compilation, and dissemination of regional-level European statistics. It has ensured stability and comparability for the Cohesion Policy and other territorial policy measures. From the policy side, however, there have been two main relevant developments in recent years. There is a growing need for EU-level policy makers to focus on regions and areas with specific characteristics (urban, rural, coastal, etc.).

The 'Pact of Amsterdam', adopted in 2016, established the Urban Agenda for the EU. The Agenda calls for better regulation, better funding, and better knowledge, including more reliable data for evidence-based policy making. The Cohesion Policy itself has several policy instruments focused directly on cities: sustainable urban development, URBACT, and urban innovative actions. In the post-2020 Cohesion Policy, cities will most probably play again a key role.

On the other hand, the recent reform of the EU's Common Agricultural Policy (CAP) shifted its focus toward a land-based policy. A number of CAP indicators describe the situation of rural areas, in line with the policy objective of balanced territorial development. These indicators are also essential for the programming, implementation, monitoring, and evaluation of rural development policy. For policy makers, it is particularly important to obtain these indicators by urban-rural typology. This is a precondition for the comparison of social and economic living conditions between rural, intermediate, and urban areas.

Regional Statistics, Vol. 7. No.1. 2017: 078-089; DOI: 10.15196/RS07105 
Degree of urbanisation for local administrative units level 2

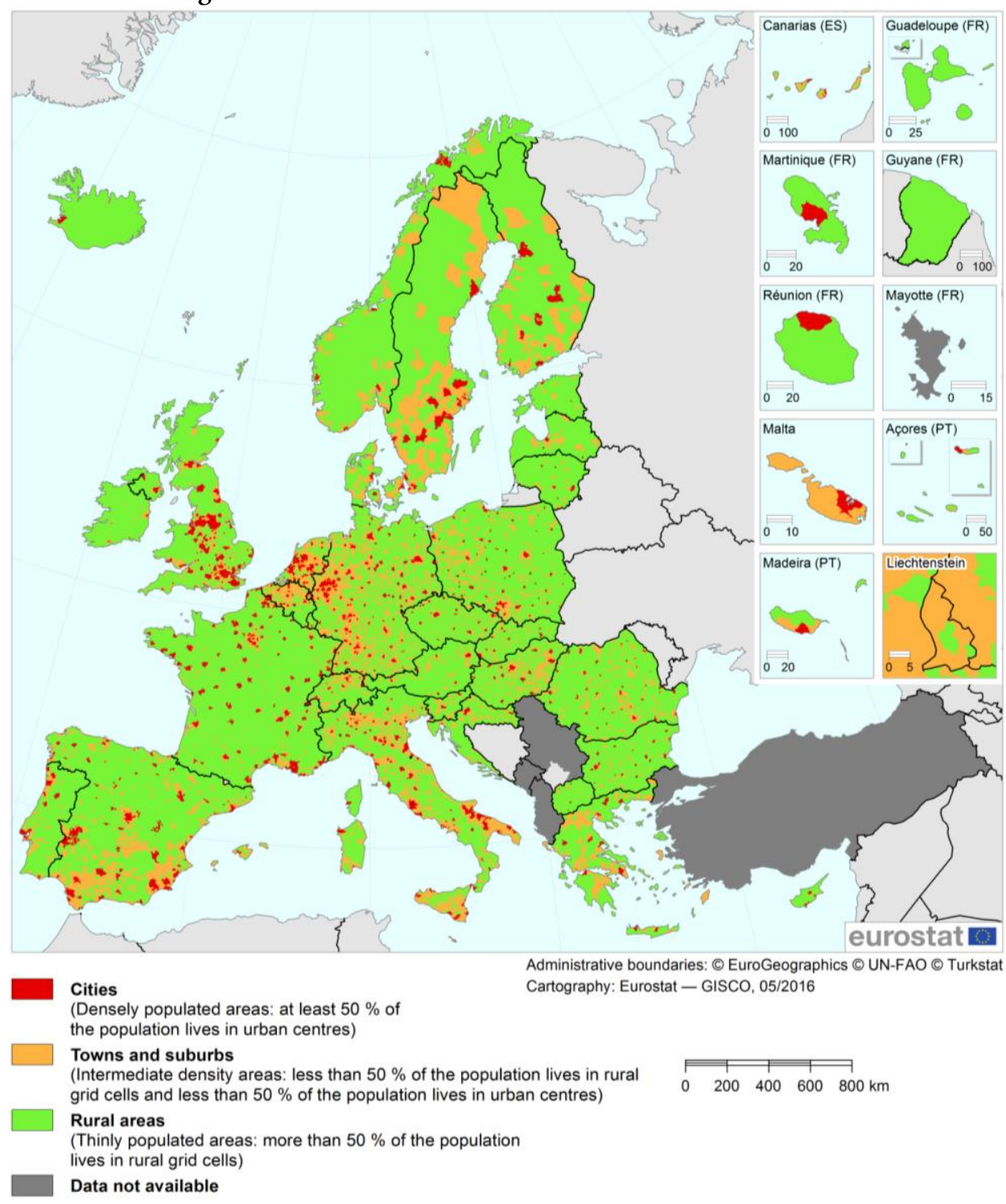

(') Based on population grid from 2011 and LAU 2014. Denmark, Greece and Malta: local administrative units level 1 (LAU1).

Source: Eurostat, JRC and European Commission Directorate-General for Regional Policy

Source: Eurostat/Territorial typologies.

To address these policy needs, the European Commission established harmonised typologies and sub-NUTS classifications, because comparability can 
only be achieved through European-level harmonisation. These tools have been used for analytical purposes. The European Commission introduced territorial typologies based on population size, geographic location, and population density to monitor situations and trends in specific regions and areas. Eurostat disseminates statistical aggregates using the following urban-rural classifications (Eurostat/Territorial typologies; see References):

- Urban-rural typology classifies the NUTS level 3 regions of the EU into three different categories: predominantly urban, intermediate, and predominantly rural. It is a geographical typology based on the definition of urban versus rural grid cells of $1 \mathrm{~km}^{2}$ each. The type of region depends on the share of the regional population living in rural grid cells.

- Degree of urbanisation classifies local administrative units (LAUs) based on the share of the local population living in urban clusters and urban centres into cities, towns and suburbs, and rural areas.

Eurostat's Statistical Atlas is an interactive viewer that allows users to study these different layers of classification, as well as statistical data, in combination with layers of geographical information (e.g. statistical regions, cities, roads, or rivers).

Eurostat's database with statistics by degree of urbanisation contains a range of population and social indicators covering the following: education and training, living conditions and welfare, the labour market, tourism, and the information society.

\section{Functional geographies}

Further challenges for regional statistics derive from the recognition that certain economic, social, and environmental phenomena do not strictly follow administrative boundaries; thus, a more flexible statistical geography is needed. Different parts of a region may have very different social conditions, or the lives of citizens are strongly influenced by the distances they have to travel to work. Mountainous and coastal areas have very different conditions that determine access to education or the job market. In administrative terms, these areas are usually combined with areas of different characteristics. With a focus based purely on administrative boundaries, the specific issues of the area in question are not as apparent as policy requirements would necessitate. Thus, the varied facets of policy actions require a picture at a different level of territorial focus - namely, a functional view.

Functional geography captures the spatial extent of a policy issue (e.g. managing a river basin or labour market area). Using functional geography can enhance the efficiency of public policies, even though it often calls for more coordination across administrative or political boundaries. To obtain a better understanding of the functional geography dimension, the European Commission developed a number of

Regional Statistics, Vol. 7. No.1. 2017: 078-089; DOI: 10.15196/RS07105 
new harmonised territorial definitions and continues to work on new ones. Together with the OECD, it has created a new harmonised definition of a city and its commuting area which shows that the latter, especially in large cities, often cross NUTS region boundaries and even national borders. Another prominent example is the labour market area (LMA): a geographic area defined for the purposes of compiling, reporting, and evaluating employment, unemployment, workforce availability, and related topics. Commuting patterns are the primary consideration in defining and delineating LMAs. LMAs are potentially the most appropriate spatial units thus far for examining spatial phenomena such as labour mobility and labour market development, as well as the spatial relationships of neighbouring municipalities in terms of the EU's free labour market.

\section{Merging statistics and geographical information: New possibilities for statistical analysis}

In contrast to regional or urban statistics, the area analysed in 'Spatial Statistics' is not fixed from the start but flexibly determined based on topological, geometric, geographic, or statistical properties. Starting from the spatial location of the phenomena being studied, the analysis is applied precisely to the area considered most appropriate for understanding the phenomena in question. For example, for analysing certain health-related issues, the different locations of individuals, their residences, their workplaces, or their routes to work can be used in flexible ways and combined with user-defined areas most suitable for the characteristics to be studied.

Spatial statistics originates from technological progress as well as from a growing awareness of possibilities following the introduction of some widely popular applications based on spatial information. The technological basis for geographic information systems (GIS) has changed radically in recent years, creating new possibilities, although the concept and technology are by no means new in principle. Spatial datasets are often very large, amounting to gigabytes of data that need to be not only stored but also manipulated in flexible and efficient ways. Progress in data storage, database technology, and IT processing speed moved the field of GIS from data centres to desktop computers, while at the same time specialised GIS software became more mature and easier to use.

The use of maps and spatial information is far from new. Each city has a cadastral office, and maps in general were always used for planning purposes. However, the ease of access and processing of such data in modern IT systems has introduced spatial data into many new application areas.

Evident uses of spatial statistics are local, such as planning by communal administrations, planning streets to minimise environmental impact, or planning bus stops to optimise their utility for citizens. Maps and spatial analysis are also

Regional Statistics, Vol. 7. No.1. 2017: 078-089; DOI: 10.15196/RS07105 
indispensable for disasters, such as flooding or large-scale fires, in order to show the impact in detail without losing the larger perspective.

Spatial statistics and analysis are also useful for subjects requiring a large-scale perspective to explore the characteristics of regions that were not initially identified in the same way. For example, a geocoded survey originally intended for administrative regions may allow for studying differences between rural and urban regions.

\section{The grid-based perspective}

The grid-based perspective is particularly useful for statistical purposes because it allows, on the one hand, the application of a very detailed geographical perspective. On the other hand, it preserves statistical confidentiality by not disclosing the characteristics of individual statistical units. Statistical grid data are statistics geographically referenced to a system of (usually squared) grid cells in a grid net with Cartesian coordinates. Traditionally, official statistics are reported in accordance with a hierarchical system of administrative units. In the EU, NUTS is the most important example of such an output system. While this is excellent for many purposes - like reporting to the respective authority administering the territory - it is not suitable for studying the causes and effects of many socioeconomic and environmental phenomena, such as flooding, commuting, etc.

Population density is one subject that can be well displayed in terms of grids. Reliable population density grids allow for a flexible delineation of areas of interest. Consequently, it becomes much easier for researchers and analysts to combine statistical data with scientific data. In addition, such a system will provide for temporal stability in the statistical reference system. Potential users range from local to national authorities, the EU, businesses, and researchers. In particular, all statistics related to individuals will profit from the availability of high-resolution population data.

\section{Conclusions}

Since 2010, the quantity and quality of regional and other sub-national data from official statistics have significantly improved due to the efforts of the National Statistical Institutes and Eurostat. The domain has also benefited from data from other sources, such as the Joint Research Centre, Copernicus, the European Space Agency, the European Environmental Agency, and the Directorate-General for Regional and Urban Policy, among others. This has led to better data on a wide range of issues, including poverty, well-being, health, air quality, innovation, access to public transport, and the structure of settlements. However, more remains to be done to complete the picture and provide more detail. With technological progress in geocoding units of the economy, society, and environment, the availability of

Regional Statistics, Vol. 7. No.1. 2017: 078-089; DOI: 10.15196/RS07105 
information at the lowest level of geographical resolution is increasing, creating new opportunities for regional and sub-national statistics. Big data can also help to better fulfil the mandate of providing timely and coherent statistics for decision making, research, and public debate in the future.

EU policy making increasingly focuses on sub-national aspects based on the understanding that sub-national analyses play an important role in achieving an integrated economic and social space. Deeper analyses of social and economic conditions (e.g. those required for focused cohesion projects) need to look to functionally defined regions to complement the administrative perspective of administrative regions.

Statistics and geographic information are naturally related. Statistics are intrinsically geo-referenced information since they refer to specific geographic entities such as states, regions, and cities. The explicit link with more detailed and fine-grained geographic information is, therefore, a rather natural extension of statistics.

The different forms of sub-national statistics presented should not be seen as isolated and distinct types of statistical or geographic information. They are in many ways integrated and complementary.

\section{Disclaimer}

All statements in this article are provided for information purposes only. They do not constitute an official policy position of the European Commission and are not legally binding. Content published on the Eurostat website was used to draft this article. Such instances are not individually referenced.

\section{REFERENCES}

Eurostat (2017): Eurostat / Regions and Cities Illustrated (RCI) Luxembourg. http://ec.europa.eu/eurostat/cache/RCI/\#?vis=nuts2.labourmarket\&lang=en (downloaded: 7 April 2017)

Eurostat (2017): Eurostat / Territorial typologies - Statistics Explained Luxembourg. http:/ /ec.europa.eu/eurostat/statisticsexplained/index.php/Territorial_typologies (downloaded: 7 April 2017)

Eurostat (2017): Eurostat /Statistical Atlas Luxembourg. http://ec.europa.eu/ eurostat/statistical-atlas/gis/viewer/?config=RYB-2016.json\&mids= 2,18,CNTR-OVL\&o=1,1,0.7\&center=50.03696,19.9883,3\& (downloaded: 7 April 2017)

HALdorson, M.-ZACCHeddu, P.-Fohgrub, B.-Petri, E. (2016): Geospatial information management in Europe - responding to the user needs Statistical Journal of the IAOS 32 (4):481-487.

European Commission (2014) Dijkstra L. (ed.) Investment for jobs and growth, Sixth Report on economic, social and territorial cohesion Brussels.

Regional Statistics, Vol. 7. No.1. 2017: 078-089; DOI: 10.15196/RS07105 
Dijkstra, L.-Poelman, H. (2014): A harmonised definition of cities and rural areas: the new degree of urbanisation European Commission Working Papers http://ec.europa.eu/regional_policy/sources/docgener/work/2014_01_new_ur ban.pdf (downloaded: 8 April 2017)

EUROSTAT (2016): Eurostat Regional Yearbook Luxembourg.

Consolidated version of the Treaty on the Functioning of the European Union (2012) Articles 174 to 178 OJ C 326, 26.10.2012

NUTS Regulation (EC) No 1059/2003 establishing a common classification of territorial units for statistics (NUTS) OJ L 154, 21.6.2003

Regional Statistics, Vol. 7. No.1. 2017: 078-089; DOI: 10.15196/RS07105 